doi:10.1016/j.ijpara.2006.03.001

Copyright (@ 2006 Australian Society for Parasitology Inc Published by Elsevier Ltd.

\title{
Genotyping of Giardia in Dutch patients and animals: A phylogenetic analysis of human and animal isolates *
}

\author{
J.W.B. van der Giessen ${ }^{a,{ }^{\star *}}$, A. de Vries ${ }^{a}$, M. Roos ${ }^{a}$, Peter Wielinga ${ }^{a}$, L.M. Kortbeek ${ }^{b}$ and \\ T.G. Mank ${ }^{\mathrm{C}}$

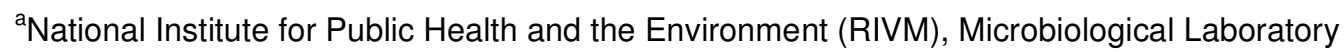 \\ for Health Protection, Antonie van Leeuwenhoeklaan 9, P.O. Box 1, Bilthoven, The \\ Netherlands \\ ${ }^{b}$ National Institute of Public Health and the Environment (RIVM), Laboratory for Infectious \\ Diseases Surveillance and Screening, Antonie van Leeuwenhoeklaan 9, P.O. Box 1, \\ Bilthoven, The Netherlands \\ 'Laboratory of Public Health, Department of Parasitology, Boerhaavelaan 26, 2035 RC, \\ Haarlem, The Netherlands
}

"Note: Nucleotide sequence data reported in this paper are available in the Genbank under the accession numbers: AY826191-AY826210; AY827496-AY827499; DQ100287, DQ100288.

${ }^{* *}$ Corresponding author. Tel.: +31 30 2743926; fax: +31 302744434.

\section{Abstract}

Giardia duodenalis (syn. Giardia lamblia, Giardia intestinalis) is a protozoan organism that can infect the intestinal tract of many animal species including mammals. Genetic heterogeneity of $G$. duodenalis is well described but the zoonotic potential is still not clear. In this study, we analysed 100 Giardia DNA samples directly isolated from human stool specimens, to get more insight in the different $G$. duodenalis assemblages present in the Dutch human population. Results showed that these human isolates could be divided into two main Assemblages $A$ and $B$ within the $G$. duodenalis group on the basis of PCR assays specific for the Assemblages $A$ and $B$ and the DNA sequences of $18 S$ ribosomal RNA and the glutamate dehydrogenase $(\mathrm{gdh})$ genes. Genotyping results showed that $G$. duodenalis isolates originating from Dutch human patients belonged in $35 \%$ of the cases to Assemblage A (34/98) and in $65 \%$ of the cases to Assemblage B (64/98) whereas two human cases remained negative in all assays tested. In addition, we compared these human samples with animal samples from the Netherlands and human and animal samples from other countries. A phylogenetic analysis was carried out on the DNA sequences obtained from these Giardia and those available in GenBank. Using gdh DNA sequence analysis, human and animal Assemblage A and B Giardia isolates could be identified. However, phylogenetic analysis revealed different sub-clustering for human and animal isolates where host-species-specific assemblages (C, D, E, F and G) could be identified. The geographic origin of the human and animal samples was not a discriminating factor.

\section{Introduction}

The flagellated protozoan Giardia is an intestinal parasite that can infect many species in the animal kingdom including mammalian, avian and reptilian wildlife, domesticated animals and humans (Thompson, 2004 and Appelbee et al., 2005). Of the morphologically defined Giardia species, Giardia muris, Giardia microti, Giardia agilis, Giardia psicatti and Giardia duodenalis (syn. Giardia lamblia, Giardia intestinalis), only the latter is recovered from humans and a wide variety of other mammals. In humans, $G$. duodenalis can cause gastrointestinal infections ranging from mild to severe as well as chronic disease. In domestic animals, $G$. duodenalis is of considerable clinical importance and could have economic significance in cattle-based industries (Olson et al., 2004). Infection occurs by faecal oral route transmission, either by direct contact or by ingestion of contaminated food or water (Monis and Thompson, 
2003). Despite morphological uniformity, considerable biotypic and genetic diversity exists within the G. duodenalis species (Monis et al., 1996 and Thompson et al., 2000). The species includes several 'assemblages' or genotypes, A-G, that can be discriminated on the basis of host selection and genomic mutations (Monis et al., 1999). Although several genes encoding proteins involved in meiosis are present in Giardia (Ramesh et al., 2005), direct evidence for sexual recombination has not yet been shown. Phylogenetic multilocus analysis using $18 \mathrm{~S}$ rRNA, glutamate dehydrogenase $(G d h)$, elongation factor 1 alpha (EF-1 $\alpha)$ and triose phosphate isomerase (Tpi) gene based molecular methods have been used on representatives of each major genetic group to study the relations among assemblages from different hosts (Monis et al., 1999, van Keulen et al., 2002 and Caccio et al., 2005). Zoonotic transmission of $G$. duodenalis is still under debate and despite increasing knowledge of the molecular identification of Giardia from different host species; the zoonotic potential of $G$. duodenalis is not clear (Monis and Thompson, 2003, Thompson, 2004 and Hunter and Thompson, 2005). One report in the literature has identified a clear animal to human transmission: waterborne transmission of Giardia from a beaver to humans was identified (Isaac-Renton et al., 1993). A survey on the transmission of Giardia from dogs to humans indicated that there was no transmission from dogs to humans but that the reverse, transmission from humans to dogs, could be possible (Hopkins et al., 1997). Dogs, however, might not only transmit human adapted Giardia genotypes as was described by a study in an endemic area where humans and dogs were living closely together (Traub et al., 2004) but may also be infected with host-adapted Giardia genotypes (Caccio et al., 2005). Studies designed to investigate zoonotic potential are still based either on limited numbers of isolates from a diverse source or limited molecular identification tools.

It was our aim to analyse the genetic diversity of Giardia isolates from human clinical cases in the Netherlands by different molecular typing methods and to compare the results of the different methods. We used the following methods: gdh PCR-restriction fragment length polymorphism (RFLP) assay and the two discriminative PCR assays. One PCR assay specifically detected Assemblage A and one was specific for Assemblage B genotypes of $G$. duodenalis as described by Homan et al. (1998). In addition, we performed DNA sequence analysis of two different genes, $18 \mathrm{~S}$ rDNA and the gdh gene. As well as the human isolates, we sequenced these loci for several animal Giardia isolates. The different sequences were used to construct a database so we could compare our findings for human patient Giardia isolates with those from animals in the Netherlands and those published previously and available in GenBank. Using phylogenetic analysis, it was our aim to further elucidate the relationship of the different genotypes to each other, their hosts and the geographic origin to study the possibilities for zoonotic transmission.

\section{Materials and methods}

\subsection{Origin of the samples}

One hundred microscopically confirmed Giardia-positive faecal samples from humans with symptoms of diarrhoea were analysed. In addition, Giardia-positive faecal samples of two dogs three sheep/goat and one Dutch roe deer from the Netherlands were analysed using the same methods (Table 1A). The details of the DNA sequences acquired from Genbank and used in this study are shown in Table 1B and Table 1C. 
International Journal for Parasitology Volume 36, Issue 7 , June 2006, Pages 849-858

Table 1A.

Giardia 18S rDNA and gdh DNA sequences submitted to Genbank for human and animal Giardia isolates determined in this study

\begin{tabular}{|l|l|l|l|l|l|}
\hline Isolate & Host & Geographical origin & 18S rRNA GenBank GI $^{\mathbf{a}}$ & GDH GenBank GI $^{\text {Assemblage }}$ \\
\hline NLH13 & Human & The Netherlands & AY826201 & AY826191 & B \\
\hline NHL20 & Human & The Netherlands & AY826204 & AY826194 & A \\
\hline NHL25 & Human & The Netherlands & AY826203 & AY826193 & B \\
\hline NHL28 & Human & The Netherlands & AY826202 & AY826192 & B \\
\hline NHL35 & Human & The Netherlands & AY826207 & AY826197 & B \\
\hline NHL37 & Human & The Netherlands & AY826206 & AY826196 & A \\
\hline NHL45 & Human & The Netherlands & AY826205 & AY826195 & A \\
\hline NLDE3 & Dog & The Netherlands & AY827497 & AY827498 & D \\
\hline NLD37 & Dog & The Netherlands & AY827496 & AY827499 & D \\
\hline NLG409 & Goat & The Netherlands & AY826210 & AY826198 & E \\
\hline NLR118 & Roe deer & The Netherlands & DQ100287 & DQ100288 & A \\
\hline NLS352 & Sheep & The Netherlands & AY826208 & AY826199 & E \\
\hline NLS387 & Sheep & The Netherlands & AY826209 & AY826200 & E \\
\hline
\end{tabular}

${ }^{a}$ GenBank accession/GI number.

${ }^{\mathrm{b}}$ Assemblage A corresponds to a positive A PCR, type $118 \mathrm{~S}$ rRNA sequence and G1 glutamate dehydrogenase (GDH) restriction fragment length polymorphism (RFLP), Assemblage B to a positive B PCR, type 2 18S rRNA sequence and G2 GDH RFLP.

Table 1B.

DNA sequences from Giardia infecting humans, acquired from Genbank and used in this study

\begin{tabular}{|l|l|l|l|l|l|}
\hline Isolate & $\begin{array}{l}\text { Geographical } \\
\text { origin }\end{array}$ & $\begin{array}{l}\text { 18S rRNA } \\
\text { GenBank } \\
\text { GI }\end{array}$ & $\begin{array}{l}\text { GDH } \\
\text { GenBank } \\
\text { GI }\end{array}$ & Genotype & Reference \\
\hline BAH-12 & Australia & AF113897 & AF069059 & B,III & Monis (1999), Thompson (2000) \\
\hline Ad-2 & Australia & & L40510 & A,II & Monis (1996) \\
\hline Ad-28/Ad-19 & Australia & AF113898 & L40508 & B,IV & Monis (1996, 1999) \\
\hline BaH40c11 & Australia & AF199446 & & A & Thompson (2000) \\
\hline Ad-113 & Australia & & AY178736 & A2 & Ey (2002), Unpublished data \\
\hline Bris-136 & Australia & & AY178737 & A2 & Ey (2002), Unpublished data \\
\hline Ad-1 & Australia & & AY178735 & A1 & Ey (2002), Unpublished data \\
\hline Ad-28 & Australia & & AY178738 & B & Ey (2002), Unpublished data \\
\hline Ad-45 & Australia & & AY178739 & B & Ey (2002), Unpublished data \\
\hline Ad-85 & Australia & & AY178755 & B3 & Ey (2002), Unpublished data \\
\hline Ad-82 & Australia & & AY178754 & B0 and B3 & Ey (2002), Unpublished data \\
\hline FCQ-21 & Australia & & AY178756 & B3 & Ey (2002), Unpublished data \\
\hline Bris/91/Hepu1279 & Australia & L29192 & & & Upcroft (1994) \\
\hline CA1 & China & AJ293296 & & A & Yong (2000) \\
\hline CA8 & China & AJ293300 & & B & Yong (2000) \\
\hline CA13 & China & AJ293299 & & A & Yong (2000) \\
\hline CA14 & China & AJ293297 & & A & Yong (2000) \\
\hline CA18 & China & AJ293298 & & A & Yong (2000) \\
\hline K2 & South Korea & AJ293295 & & A & Yong (2000) \\
\hline K-C1 & South Korea & AJ293301 & & A & Yong (2000) \\
\hline Portland1 & South Korea & M54878 & M84604 & 1, A-I & Sogin (1989) \\
\hline AMC-4 & The Netherlands & U09491 & & B & van Keulen (1995) \\
\hline & & & & & \\
\hline
\end{tabular}

${ }^{a}$ Genotype as listed in the references. 
International Journal for Parasitology Volume 36, Issue 7 , June 2006, Pages 849-858

Table 1C.

DNA sequences from Genbank from various parasitic animal Giardia used in this study

\begin{tabular}{|c|c|c|c|c|c|c|}
\hline Isolate & Host & $\begin{array}{l}\text { Geographical } \\
\text { origin }\end{array}$ & $\begin{array}{l}\text { 18S rRNA } \\
\text { GenBank } \\
\text { GI }\end{array}$ & $\begin{array}{l}\text { GDH } \\
\text { GenBank } \\
\text { GI }\end{array}$ & Genotype $^{b}$ & Reference \\
\hline Blue heron & $\begin{array}{l}\text { Blue } \\
\text { heron }\end{array}$ & USA & Z17210 & & $\begin{array}{l}\text { Giardia } \\
\text { ardeae }\end{array}$ & $\begin{array}{l}\text { van Keulen } \\
\text { (1993) }\end{array}$ \\
\hline Ad-133 & Calf & Australia & & AY178740 & $E$ & $\begin{array}{l}\text { Ey (2002), } \\
\text { Unpublished data }\end{array}$ \\
\hline Ad-23 & Cat & Australia & AF113910 & AF069057 & Cat & Monis (1999) \\
\hline Ad-131 & Cat & Australia & & AY178742 & Cat & $\begin{array}{l}\text { Ey (2002), } \\
\text { Unpublished data }\end{array}$ \\
\hline Ad-142 & Cat & Australia & & AY178743 & Cat & $\begin{array}{l}\text { Ey (2002), } \\
\text { Unpublished data }\end{array}$ \\
\hline Ad-154 & Cat & Australia & & AY178744 & Cat & $\begin{array}{l}\text { Ey (2002), } \\
\text { Unpublished data }\end{array}$ \\
\hline $\mathrm{CH}-105$ & Chinchilla & Czech Rep. & & AY178751 & B1 & $\begin{array}{l}\text { Ey (2002), } \\
\text { Unpublished data }\end{array}$ \\
\hline Ad-136 & Dog & Australia & AF113899 & U60982 & $\mathrm{C}$ & Monis (1999) \\
\hline Ad-148 & Dog & Australia & AF113900 & U60986 & $\mathrm{D}$ & Monis (1998) \\
\hline Ad-137 & Dog & Australia & & U60983 & $\mathrm{C}$ & Monis (1998) \\
\hline Ad-141 & Dog & Australia & & U60984 & $\mathrm{C}$ & Monis (1998) \\
\hline Ad-147 & Dog & Australia & & U60985 & C & Monis (1998) \\
\hline dog6 & Dog & Australia & AF199443 & & Group 4 & Thompson (2000) \\
\hline $\operatorname{dog} 19$ & Dog & Australia & AF199449 & & Group 3 & Thompson (2000) \\
\hline Vanc/89/UBC/059 & Dog & Canada & & AY178750 & $\mathrm{B}$ & $\begin{array}{l}\text { Ey (2002) } \\
\text { Unpublished, } \\
\text { Monis (1998) }\end{array}$ \\
\hline CZ:D-47 & Dog & Czech Rep. & & AY178749 & B & $\begin{array}{l}\text { Monis (1999), Ey } \\
\text { (2002), } \\
\text { Unpublished data }\end{array}$ \\
\hline GF-1 & Ferret & Japan & AB159796 & AB159795 & $A$ & Abe (2005) \\
\hline BAG1 & Goat & Australia & AF199448 & & Lifestock & Thompson (2000) \\
\hline PRM 025 & Ibis & Australia & U20351 & & $\begin{array}{l}\text { Giardia } \\
\text { ardeae }\end{array}$ & McRoberts (1996) \\
\hline Ad-156 & Marmoset & Australia & & AY178752 & B2 & $\begin{array}{l}\text { Ey (2002), } \\
\text { Unpublished data }\end{array}$ \\
\hline Ad-158 & Marmoset & Australia & & AY178753 & B2 & $\begin{array}{l}\text { Ey (2002), } \\
\text { Unpublished data }\end{array}$ \\
\hline Ad-170 & Mouse & Australia & & AY178748 & & $\begin{array}{l}\text { Ey (2002), } \\
\text { Unpublished data }\end{array}$ \\
\hline $\begin{array}{l}\text { Peromyscus } \\
\text { leucopus }\end{array}$ & $\begin{array}{l}\text { (deer) } \\
\text { Mouse }\end{array}$ & USA & AF473852 & & $\begin{array}{l}\text { Giardia. } \\
\text { Microti }\end{array}$ & $\begin{array}{l}\text { van Keulen } \\
(2002)\end{array}$ \\
\hline $\begin{array}{l}\text { Ondatra } \\
\text { zibethicus }\end{array}$ & Muskrat & USA & AF006677 & & G. microti & $\begin{array}{l}\text { van Keulen } \\
\text { (1998) }\end{array}$ \\
\hline Parakeet & Parakeet & USA & AF473853 & & $\begin{array}{l}\text { Giardia } \\
\text { psittaci }\end{array}$ & $\begin{array}{l}\text { van Keulen } \\
\text { (2002) }\end{array}$ \\
\hline $\begin{array}{l}\text { Microtus } \\
\text { ochrogaster }\end{array}$ & $\begin{array}{l}\text { Prairie } \\
\text { vole }\end{array}$ & USA & AF006676 & & G. microti & $\begin{array}{l}\text { van Keulen } \\
(1998)\end{array}$ \\
\hline Ad-157 & Rat & Australia & AF113896 & AF069058 & Rat & Monis (1999) \\
\hline Ad-155 & Rat & Australia & & AY178745 & Rat & $\begin{array}{l}\text { Ey (2002), } \\
\text { Unpublished data }\end{array}$ \\
\hline Ad-167 & Rat & Australia & & AY178746 & Rat & $\begin{array}{l}\text { Ey (2002), } \\
\text { Unpublished data }\end{array}$ \\
\hline Ad-171 & Rat & Australia & & AY178747 & Rat & $\begin{array}{l}\text { Ey (2002), } \\
\text { Unpublished data }\end{array}$ \\
\hline Rat2 & Rat & Australia & AF199450 & & Rat & Thompson (2000) \\
\hline
\end{tabular}

${ }^{\mathrm{b}}$ Genotype as listed in the references. 


\subsection{DNA isolation}

Total DNA from Giardia cysts from fresh non-preserved stool samples was isolated as described earlier (Homan et al., 1998) with some modifications. Briefly, stools were broken up in distilled water and filtered through a $70 \mu \mathrm{m}$ cell strainer (BD Falcon, Belgium), $2.5 \mathrm{ml}$ stool suspensions were layered on $3 \mathrm{ml}$ of $1.6 \mathrm{M}$ sucrose and centrifuged at $750 \times g$ for $5 \mathrm{~min}$. Cysts at the sucrose-water interphase were collected and washed with distilled water. The enriched cysts were resuspended in $1 \mathrm{ml}$ distilled water and $100 \mu \mathrm{l}$ of $10 \times$ buffer $A, 100 \mu$ l of $10 \times$ buffer $\mathrm{B}$ and $10 \mu \mathrm{l}$ anti-Giardia magnetic beads provided with the Giardia/Cryptosporidium purification kit (Dynal Biotech GmbH, Hamburg, Germany). After $1 \mathrm{~h}$ of gently mixing the suspension at room temperature the magnetic beads were washed with buffer $A$ using a tubeholder with a magnetic strip (Dynal Biotech). For DNA isolation the beads were resuspended in $600 \mu \mathrm{l}$ lysis buffer provided with the Puregene kit (Gentra systems, Minneapolis, Minnesota, USA). Cysts were lysed by five freeze/thaw cycles by exposing them to dry-ice ethanol followed by heating to $65{ }^{\circ} \mathrm{C}$ and the DNA was further purified according to the manufacturer's instructions.

\subsection{Molecular analysis of samples}

Genotyping of the Giardia samples was performed by two PCR assays specific for Assemblages A and B, which we call the A- and B-PCR, respectively, and by a PCR-RFLP analysis of the $g d h$ described by Homan et al. (1998). For DNA sequence analysis of the $18 \mathrm{~S}$ rDNA gene, the PCR described by van Keulen et al. (2002) was used, amplifying 298 bases of the $5^{\prime}$ end of the $18 \mathrm{~S}$ rDNA gene. PCR reactions of the $g d h$ (human samples using primers gdh-1 and gdh-4; animal samples using primers gdh-1 and gdh-3) and the A (primers: P1F and $\mathrm{P} 3 \mathrm{R}$ ) and $\mathrm{B}$ (primers: $\mathrm{B} 1 \mathrm{~F}$ and $\mathrm{B} 3 \mathrm{R}$ ) loci were conducted in $50 \mu \mathrm{l}$ reactions mixtures containing: $10 \mathrm{mM}$ Tris- $\mathrm{HCl} \mathrm{pH} \mathrm{8.3,50} \mathrm{mM} \mathrm{KCl,} 2 \mathrm{mM} \mathrm{MgCl}$ 2, $5 \%$ dimethyl sulfoxide (Sigma), $0.1 \mathrm{mM}$ of each dNTP, $1 \mathrm{U}$ of AmpliTaq polymerase (Applied Biosystems, The Netherlands), $0.5 \mu \mathrm{M}$ of each primer and $5 \mu \mathrm{l}$ template DNA. The PCR was carried out with the following conditions: one cycle of $94^{\circ} \mathrm{C}$ for $5 \mathrm{~min}$ followed by 35 cycles of $95{ }^{\circ} \mathrm{C}$ for $1 \mathrm{~min}$, $50{ }^{\circ} \mathrm{C}$ for $1 \mathrm{~min}$ and $72{ }^{\circ} \mathrm{C}$ for $1 \mathrm{~min}$, followed by one cycle of $10 \mathrm{~min}$ and $72{ }^{\circ} \mathrm{C}$. Primers used in this study are listed in Table 2.

Table 2.

Primers used in genotyping and sequencing

\begin{tabular}{|c|c|c|c|}
\hline Locus & Primers & Position & Sequence \\
\hline \multirow[t]{3}{*}{ Gdh } & Forward gdh-1 & $362-382$ & 5'-ATCTTCGAGAGGATGCTTGAG-3' \\
\hline & Reverse gdh-4 & $1120-1140$ & 5'-AGTACGCGACGCTGGGATACT-3' \\
\hline & Reverse gdh-3 & $870-890$ & 5'-TGTCCTTGCACATCTCCTCCA-3' \\
\hline \multirow[t]{2}{*}{ A } & Forward P1F & & 5'-CTGCAGGGGCAAGGCGTAGAT-3' \\
\hline & Reverse P3R & & 5'-CCACCGTGCCAGTCTTCTGGG-3' \\
\hline \multirow[t]{2}{*}{ B } & Forward B1F & & 5'-CTGCAGTAACACTGGCAAG-3' \\
\hline & Reverse B3R & & 5'-CTGCAGAGTCTCCGCAGCG-3' \\
\hline \multirow[t]{2}{*}{ 18S rDNA } & Forward 18S-1 & $3-21$ & 5'-TCCGGTCGATCCTGCCGGA-3' \\
\hline & Reverse 18S-A & $285-301$ & 5'-GCTCTCCGGAGTCGAAC-3' \\
\hline
\end{tabular}

PCR products were purified using a Qiaquick gel extraction kit (Qiagen, Westburg, The Netherlands), according to manufacturer's instructions. DNA sequencing reactions were performed in both directions using BigDye Terminator v3.1 (Applied Biosystems, The Netherlands). To perform sequencing of the 18S rDNA PCR product the forward primer 18S-1 and reverse primer 18S-A were used. For gdh sequencing, forward primer gdh1 and reverse primer gdh3 were used (Table 2). DNA sequences were stored and analysed using the software package BioNumerics of Applied Maths (Ghent, Belgium). Representative DNA sequences were submitted to GenBank (Table $1 \mathrm{~A}$ ). For phylogenetic analysis, DNA sequences from this study were used together with DNA sequences from the same loci obtained from GenBank (Table 1B and Table 1C). Phylogenetic DNA sequence analyses were performed by maximum parsimony tree calculation and bootstrap analysis. For the 
combined or multilocus comparison of the 18S rDNA and the gdh sequences, one phylogenetic tree was generated using cluster analysis with the unweighted pair group method with arithmetic mean (UPGMA) as dendrogram type.

\section{Results}

\subsection{Genotyping of human Giardia isolates}

Giardia-positive human stool samples (100 isolates) were genotyped by the Assemblage Aand B-specific PCR, gdh-PCR and RFLP. In addition, an 18S rDNA and $g d h$-specific DNA sequence analysis was performed. Clearly two genotype groups could be recognised, similar to the two assemblages A and B described by Homan et al. (1998) and Monis et al. (1999) (Table 3). In total, 34 samples were identified as Giardia Assemblage A, 64 as Assemblage B and two samples remained negative. The gdh RFLP identified 33 human samples as G1 and 55 as $\mathrm{G} 2$ type; one sample both $\mathrm{G} 1$ and $\mathrm{G} 2$; 11 samples were negative with this method. Comparing the gdh RFLP results with the assemblage A- and B-specific PCR results showed that except for two samples all $33 \mathrm{G} 1$ positive samples were positive in the A-PCR. One of the $\mathrm{G} 1$ isolates remained negative and one was positive in both the A- and B-specific PCR. The G2 samples only showed a positive result in the B-PCR. The 18S rDNA sequence analyses showed that $18 \mathrm{~S}$ rDNA type 1 sequences were linked both to the Assemblage Aspecific PCR samples and G1 positive samples. The 18S rDNA type 2 sequences were linked both to the Assemblage B-specific PCR samples and G2 positive human samples (Table 3). Of the 11 negative gdh RFLP samples one could be identified by the 18S rDNA sequence as type 1 Giardia isolate and eight as type 2 Giardia isolates. For one human sample, the gdh RFLP analysis revealed a combined G1 and G2 type, whereas in 18S rDNA sequence analysis this sample was identified as type 2 and thus was categorised in the Assemblage B.

Table 3.

Genotypic classification of 98 Giardia isolates originating from 100 clinical human patients

\begin{tabular}{|c|c|c|c|c|}
\hline Patient isolate & Assemblage $^{a}$ & 18S rRNA & $g d h$ & A/B PCR ${ }^{b}$ \\
\hline $1-29$ & A & Type 1 & G1 & A \\
\hline $30-31$ & A & Type 1 & G1 & $A+B$ \\
\hline $32-33$ & A & Type 1 & G1 & Neg \\
\hline 34 & $\mathrm{~A}(n=34)$ & Type 1 & $\mathrm{Neg}^{\mathrm{C}}$ & Neg \\
\hline $35-84$ & $\mathrm{~B}$ & Type 2 & G2 & $\mathrm{B}$ \\
\hline 85 & $B$ & Type 2 & G2 & Neg \\
\hline 86 & $\mathrm{~B}$ & Type 2 & $\mathrm{G} 2+\mathrm{G} 1$ & Neg \\
\hline $87-94$ & $B$ & Type 2 & $\mathrm{Neg}$ & $\mathrm{Neg}$ \\
\hline $95-97$ & $\mathrm{~B}$ & Neg & G2 & B \\
\hline 98 & $\mathrm{~B}(n=64)$ & Neg & G2 & Neg \\
\hline
\end{tabular}

${ }^{a}$ Assemblage A indicates a 18 S type 1, G1, positive A PCR, Assemblage B type 2, G2, positive B PCR. Negative and inconclusive/mixed samples were not considered. Between brackets the total number $(n)$ of each assemblage is given.

${ }^{\mathrm{b}} \mathrm{An} A$ indicates the sample was positive in the A PCR and negative in the B PCR, for $B$ vice versa.

${ }^{c}$ Neg: no PCR product was obtained, for two patients' isolates this was the case for all three methods used.

For confirmation purposes, three of the Dutch human Giardia isolates (randomly chosen based on A and B PCR positivity) were sent to Dr R.C.A. Thompson at the WHO Centre in Australia, who confirmed our genotyping results.

Next to the 18S rDNA sequence comparison of Giardia isolates, which showed only two slightly different sequences linked to Assemblages A and B, diversity within the gdh DNA sequences analysed was much larger. We identified seven different gdh DNA sequences. Representatives of these seven different $g d h$ sequences were submitted to GenBank and are 
shown in Table 1A. For Assemblage A, we identified three different representative gdh sequences (NHL20, NHL37, NHL45) and for Assemblage B, four different representative sequences (NHL13, NHL25, NHL28, NHL35).

\subsection{Genotyping of animal derived Giardia isolates by gdh and 18S rRNA sequences}

In addition to the set of human samples, we tested several Giardia-positive animal samples from the Netherlands. Two dog samples (NLDE3, NLD37), one goat sample (NLG409), two sheep samples (NLS352, NLS387) and one roe deer sample (NRL118). Results of PCR and DNA sequence analyses showed that the roe deer Giardia isolate belonged to Assemblage A. The dog Giardia isolates belonged to Assemblage D, while the goat and sheep isolates belonged to Assemblage $E$ (Table $1 \mathrm{~A}$ ). These results confirm the previously described hostspecific assemblages for dogs and livestock (Thompson, 2004).

\subsection{Phylogenetic analysis of $18 \mathrm{~S}$ rRNA and gdh DNA sequences}

From 18S rDNA sequences determined in this study, 229 nucleotides of representative sequences were aligned with a set of similar sequences from GenBank and were subjected to phylogenetic analysis using BioNumerics analysis software. Fig. 1 shows the phylogenetic tree resulting from 42 different Giardia 18S rDNA sequences. The tree is largely divided in seven clusters. The first cluster contains the human Assemblage A type isolated together with the cat (Assemblage F) and the livestock cluster (Assemblage E). The second cluster contains the human Assemblage $B$ isolates and third and fourth are the dog clusters of either Assemblages $\mathrm{C}$ or $\mathrm{D}$. The fifth contains the rat (Assemblage $\mathrm{G}$ ) cluster, which was supported by a bootstrap analysis at $68 \%$. The longest branches of the tree were the lineages giving rise to G. psittaci and G. ardeae (67\% bootstrap support). Finally, G. microti isolates clustered together ( $84 \%$ bootstrap support). Besides the last three clusters, all other clusters were poorly supported by bootstrap analysis.

Similar to the $18 \mathrm{~S}$ rDNA sequence comparison, we analysed a $399 \mathrm{bp}$ fragment of the $\mathrm{g} d \mathrm{~h}$ gene of 47 different Giardia isolates. This resulted in a more specific division of clusters (Fig. 2) compared with the $18 \mathrm{~S}$ rDNA analysis, indicated by higher bootstrap values for the different clusters. Again, human gdh DNA sequences belonging to either Assemblages A or B divided in two separate clusters, supporting the differentiation of the Assemblages A and B. The Dutch goat and sheep samples clustered together with the calf isolate (AY178740), Assemblage E and far distant from the Dutch dog samples (AY827498 and AY827499), which clustered together with the Australian dog (U60986), Assemblage D. The Dutch roe deer gdh sequence clustered together with the human isolates of Assemblage $A$, however, not in the same subcluster as the human Assemblage $A$ isolates analysed. In addition, some animal gdh DNA sequences derived from GenBank clustered together with human Assemblage B. Subgenotyping of our human Assemblage B-derived gdh sequences showed that those with GenBank accession number AY826193 were located in the cluster of Australian human isolates of Assemblage B group III (AY178756/AF069059) (Monis et al., 1999), those with accession number AY826191 clustered in Assemblage B group IV containing the Australian human isolates (AY178738/AY178739, AY178754, L40508), the Canadian and Czech dog isolates (AY178750/AY178749) and the Czech chinchilla isolates (AY178751). Our human isolates with accession numbers AY826192, AY826197 belonging to Assemblage B clustered together in the IV-like group together with the marmosets AY178752, AY178753. 


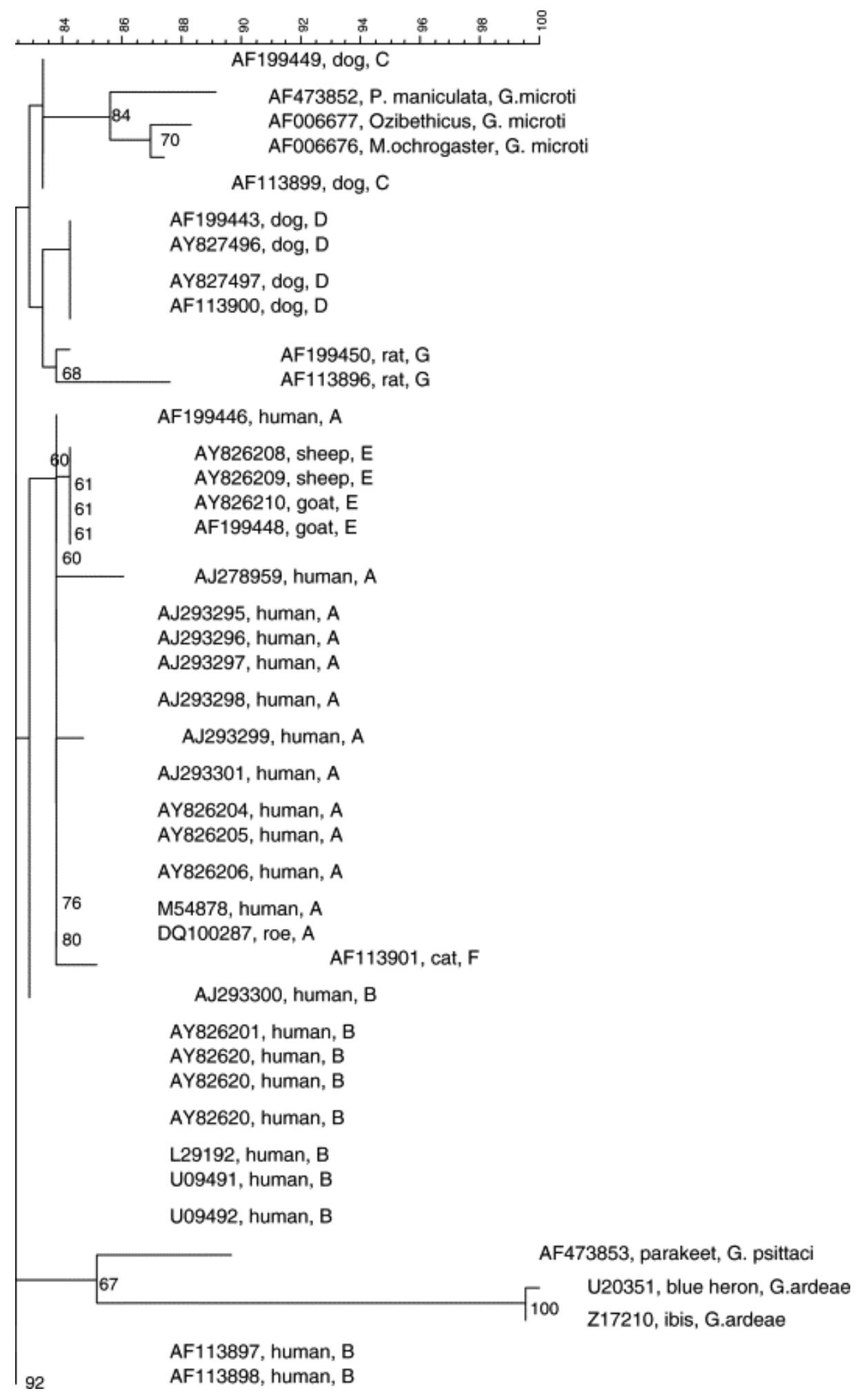

Fig. 1. Dendrogram of the phylogenetic analysis by maximum parsimony of the $18 \mathrm{~S}$ rDNA Giardia sequences of the Dutch human clinical and animal isolates determined in this study (accession numbers starting with AY82 and DQ) compared with sequences taken from GenBank (Table 1A, Table 1B and Table 1C). Percentage bootstrap support (>60\%) from 1000 replicate samples is indicated at the right of the supported node. 


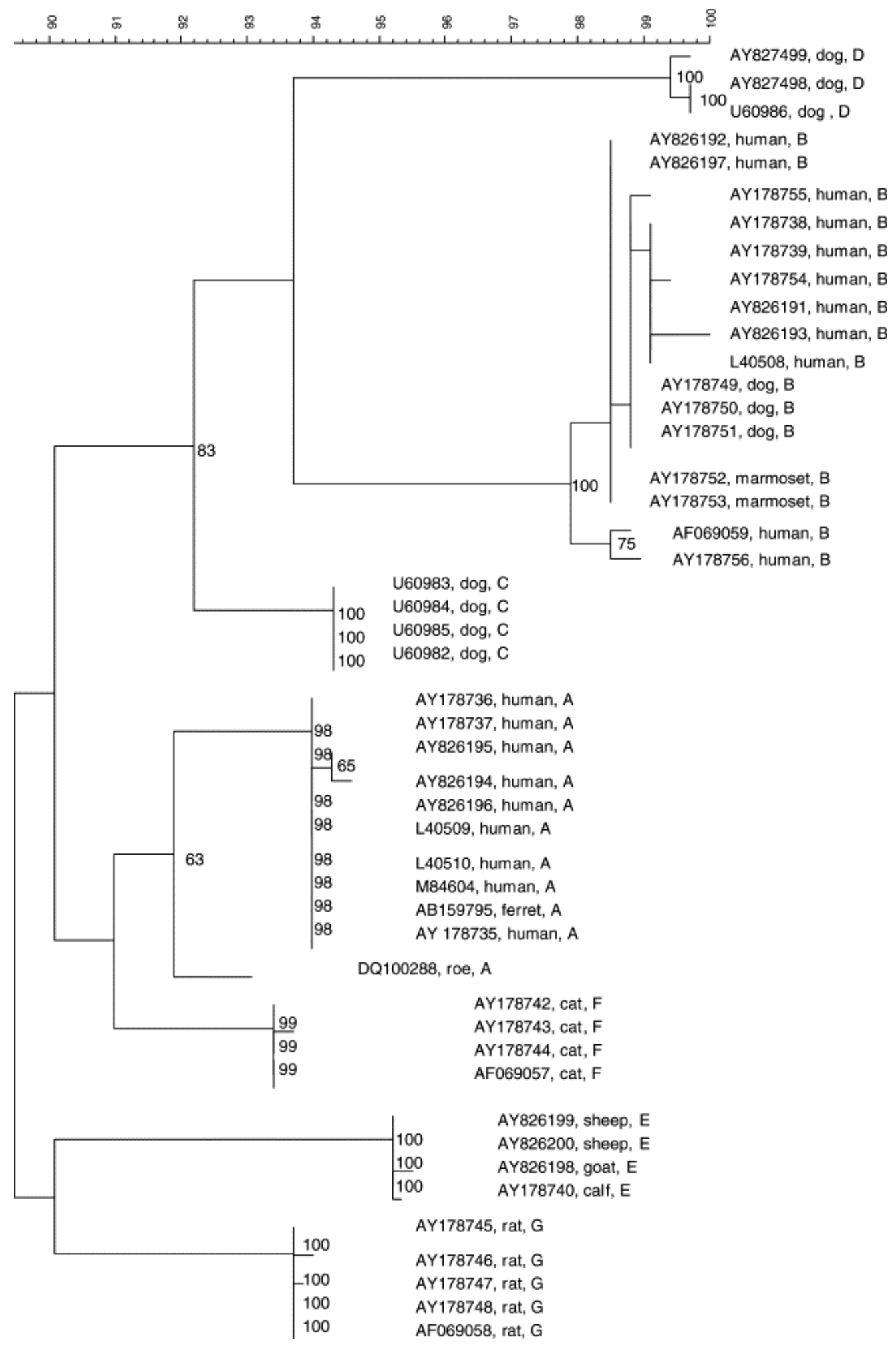

Fig. 2. Dendrogram of the phylogenetic analysis by maximum parsimony of the gdh sequences from Giardia of three different human clinical and the animal isolates determined in this study (accession numbers starting with $\mathrm{AY} 82$ and DQ) compared with sequences taken from GenBank (Table 1A, Table 1B and Table 1C). Percentage bootstrap support (>60\%) from 1000 replicate samples is indicated at the right of the supported node. 
Next, we performed a phylogenetic analysis of the combined 18S rDNA and gdh DNA sequences (Fig. 3), including only sequences from isolates that had both 18S rDNA and gdh GenBank sequence data (Table 1A, Table 1B and Table 1C). This resulted in a similar division of branches: two branches of human isolates typed as $A$ and $B$ assemblages clearly separated from each other, a branch containing goat and sheep isolates typed as Assemblage $E$, two dogs branches with the Assemblage $D$ separate from the Assemblage $C$, a rat branch of the Assemblage $G$ type and a cat branch of the Assemblage $F$ type (Fig. 2). For the branch containing the human Assemblage B isolates, the subdivision in groups III, IV and IV-like was not as detailed compared with the gdh-based tree.

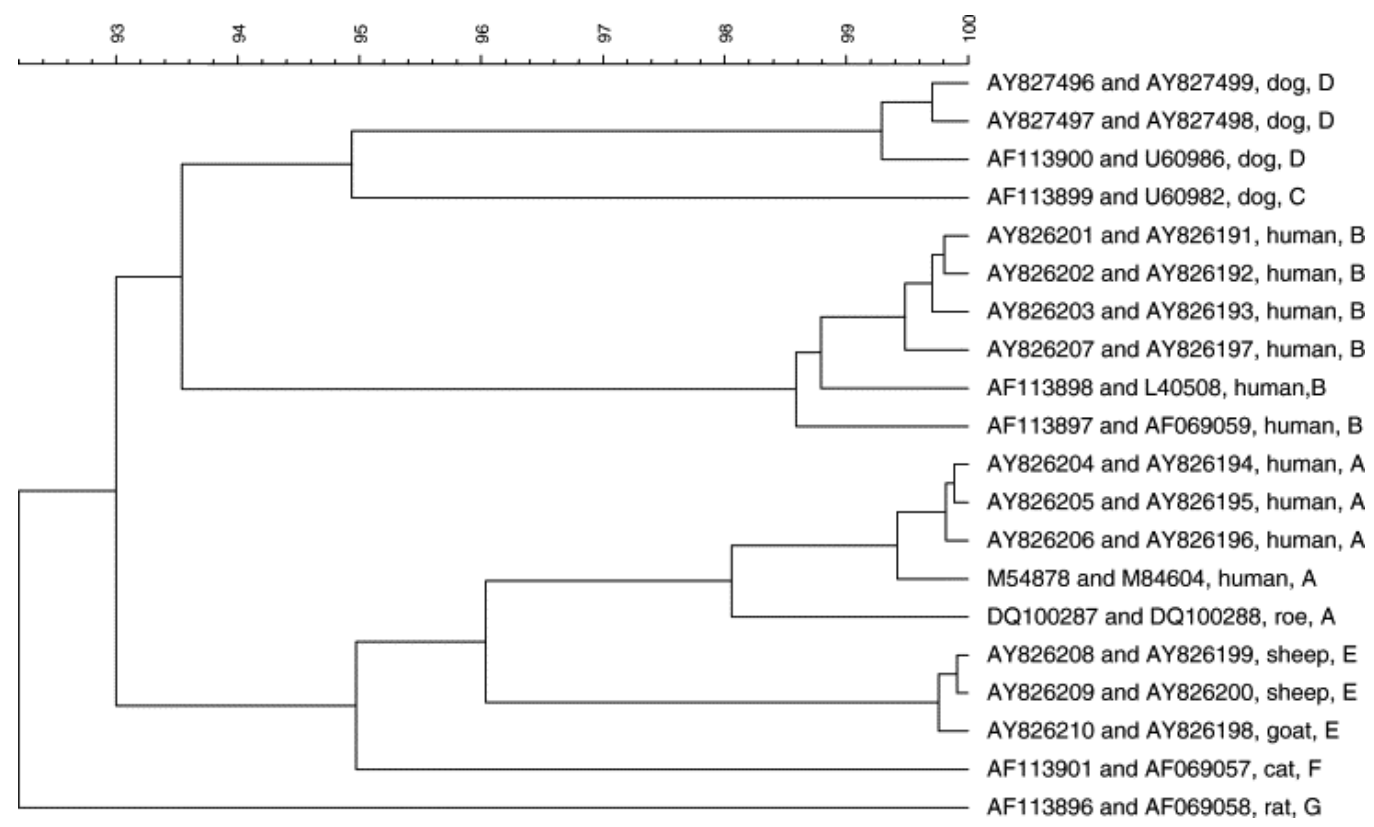

Fig. 3. Dendrogram of the multilocus phylogenetic analysis of the Giardia sequences for $g d h$ and the 18S rDNA sequences from individual isolates as determined in this study and taken from GenBank Dendrogram is constructed using the unweighted pair group method with arithmetic mean. For the multilocus analysis, no bootstrap support could be calculated.

\section{Discussion}

In the current study, we genotyped 100 different Giardia DNA samples from human stool samples in the Netherlands. Genotypic analysis showed that the Giardia samples could be divided into two major groups or Assemblages, A (35\%) and B (65\%), similar to those described before (Monis et al., 1999 and Homan and Mank, 2001). Furthermore, we compared sequences from the 18S rDNA and gdh genes from Giardia isolates from one geographic region (The Netherlands) and a large set of DNA sequences available from the literature worldwide on these genes and performed a joint phylogenetic analysis for these 18S rDNA and gdh sequences. In accordance with other references, we only isolated Assemblages $A$ and $B$ from humans in the Netherlands. In these human samples, no other Giardia species or other $G$. duodenalis assemblages were identified, indicating that only these assemblages are able to infect humans in the Netherlands. Although only a few Giardia isolates originating from Dutch animals were analysed in this study, a large set of DNA sequences are available in GenBank from animals and humans and so these were included in this study. We confirm the findings of others that $18 \mathrm{~S}$ rDNA sequences are useful to identify different Giardia species, however, they do not assist in the assemblage's classification for $G$. duodenalis. Genotyping by gdh-derived DNA sequences provides more detailed information within the different $G$. duodenalis assemblages. As more and more DNA sequences become available, the general picture that emerges is that each host species has its own host-specific Giardia assemblage or species but that some Giardia assemblages or species are found in more than one host. Although the typing results from different laboratories seem to agree, the 
taxonomy is still poorly resolved. Using gdh sequences in phylogenetic analysis gives more detailed information than the Assemblages A-F; however, it should be noted that this detailed information for our Assemblage $B$ based on less than $2 \%$ difference, might be too limited to make a significant differentiation between sub-clusters.

The question to which extent Giardia species are zoonotic is still unclear and under debate. An increasing number of Giardia animal-specific assemblages are being identified in phylogenetic comparisons: Assemblage $C$ and $D$ in dogs, $F$ in cats, $E$ in cattle, sheep and goats and $G$ in rats. Thus far, in humans only Giardia species of the Assemblages A and B have been identified. The Assemblage B is found also in Giardia samples isolated from different animal species (Fig. 1 and Fig. 2; Table 1C). In the phylogenetic tree of gdh sequences the human and animals isolates of Assemblage B cluster together, with their closest neighbour the dog isolates from the Assemblage $C$, but far distant from the human samples of the Assemblage A. With one exception of the ferret Assemblage A, all human isolates typed as Assemblage A cluster together for the gdh sequences analysis, with the nearest neighbour being the cat (Assemblage F) (Fig. 2). The reason that we could find only minor differences in the human isolates of Assemblage A, whereas Monis et al. (1999) described two groups within this assemblage (Al and All), might be due to the fact that we only analysed a $399 \mathrm{bp}$ gdh-derived PCR fragment, whereas Monis and colleagues analysed a $1.17 \mathrm{~kb}$ fragment. In addition, it might be due to the fact that we only included human patients with clinical symptoms of diarrhoea in our study. For reasons of comparison, it might therefore, be interesting to study Giardia assemblages from asymptomatic patients. The majority of $G$. duodenalis in livestock belongs to Assemblage $E$ and a minority to Assemblage A (Ey et al., 1997, Hunt et al., 2000, Becher et al., 2004 and Read et al., 2004; Appelbee et al, 2005; Giangaspero et al., 2005). However, in most studies the molecular identification was based on A- and B-specific PCR and not on analysing the gdh-derived DNA sequence product. Trout et al. (2004) described the presence of Assemblage A in cattle as determined by DNA sequence analysis of $18 \mathrm{~S}$ rDNA (292 bp), TPI (500 bp) and beta-giardin (750 bp) derived PCR fragments. Assemblage A was detected on $15 \%$ of all farms, with varying levels ranging from 8 to $45 \%$, concluding that calves might be a source of $G$. duodenalis infections in humans. Remarkably, we identified only one animal (roe deer) gdh DNA sequence and no other hoofed animal Assemblage A-specific gdh sequences are yet available in GenBank. The roe deer parasite $g d h$ sequence, however, did not cluster with the human isolates typed as Assemblage A, indicating that hoofed and human Giardia Assemblage A might be different. Thus far, only one animal gdh DNA sequence typed as Assemblage A has been reported in GenBank, a ferret isolate from Japan (Table 1C). More gdh sequence data might be helpful in providing additional information to study the zoonotic potential of $G$. duodenalis Assemblage $A$ and it would be interesting to analyse more of these gdh-derived Assemblage A DNA sequences of hoofed animals for the possibility of finding more Assemblage $A$ in this group. Furthermore, other loci like non-coding sequences and microsatellites, which tend to have a higher mutation rate, may help in finding polymorphisms to make a more significant further subdivision of Giardia and elucidate the question of zoonotic potential for Giardia. This might also give us better tools to study outbreak investigations, transmission routes and eventually to settle the issue of zoonotic transmission.

\section{Acknowledgements}

We would like to thank Dr R.C.A. Thompson of the WHO Collaborating Centre for the Molecular Epidemiology of Parasitic Infections in Australia for comparing our genotyping methods. We would like to thank Annet Heuvelink for providing the Dutch hoofed animal Giardia samples. This study was performed by order of and for the account of the Dutch Food and Product Safety Authority (VWA). 


\section{References}

Abe et al., 2005 N. Abe, C. Read, R.C. Thompson and M. Iseki, Zoonotic genotype of Giardia intestinalis detected in a ferret, J. Parasitol. 91 (2005), pp. 179-182.

Appelbee et al., 2005 A.J. Appelbee, R.C. Thompson and M. Olson, Giardia and Cryptosporidium in mammalian wildlife-current status and future needs, Trends Parasitol. 21 (2005), pp. 370-376.

Becher et al., 2004 K.A. Becher, I.D. Robertson, D.M. Fraser, D.G. Palmer and R.C.A. Thompson, Molecular epidemiology of Giardia and Cryptosporidium infections in dairy calves originating from three sources in Western Australia, Vet. Parasitol. 123 (2004), pp. 1-9.

Caccio et al., 2005 S.M. Caccio, R.C.A. Thompson, J. McLaughlin and H.V. Smith, Unravelling Cryptosporidium and Giardia epidemiology, Trends Parasitol. 21 (2005), pp. 430-437.

Ey et al., 1997 P.L. Ey, M. Mansouri, E. Nohynkova, P.T. Monis, R.H. Andrews and G. Mayrhofer, Genetic analysis of Giardia from hoofed animals reveals artiodactyl-specific and potentially zoonotic genotypes, J. Eukariot. Microbiol. 44 (1997), pp. 626-635.

Giangaspero et al., 2005 A. Giangaspero, B. Paoletti, R. lorio and D. Traversa, Prevalence and molecular characterization of Giardia duodenalis from sheep in central Italy, Parasitol. Res. 96 (2005), pp. 32-37.

Homan and Mank, 2001 W.L. Homan and T.G. Mank, Human giardiasis: genotype linked differences in clinical symptomatology, Int. J. Parasitol. 31 (2001), pp. 822-826.

Homan et al., 1998 W.L. Homan, M. Gilsing, H. Bentala, L. Limper and F. van Knapen, Characterization of Giardia duodenalis by polymerase-chain-reaction fingerprinting, Parasitol. Res. 84 (1998), pp. 707-714.

Hopkins et al., 1997 R.M. Hopkins, B.P. Meloni, D.M. Groth, J.D. Wetherall, J.A. Reynoldson and R.C.A. Thompson, Ribosomal RNA sequencing reveals differences between the genotypes of Giardia isolates recovered from human and dogs living in the same locality, J. Parasitol. 83 (1997), pp. 44-51.

Hunt et al., 2000 C.L. Hunt, G. Ionas and T.J. Brown, Prevalence and strain differentiation of Giardia duodenalis in calves of the Manawatu and Waikato regions of North Island, New Zealand, Vet. Parasitol. 91 (2000), pp. 7-13.

Hunter and Thompson, 2005 P.R. Hunter and R.C.A. Thompson, The zoonotic transmission of Giardia and Cryptosporidium, Int. J. Parasitol. 35 (2005), pp. 1-10.

Isaac-Renton et al., 1993 J.L. Isaac-Renton, C. Cordeiro, K. Sarafis and H. Shahriari, Characterization of Giardia duodenalis isolates from a waterborne outbreak, J. Infect. Dis. 167 (1993), pp. 431-440.

McRoberts et al., 1996 K.M. McRoberts, B.P. Meloni, U.M. Morgan, R. Marano, N. Binz, S.L. Eriandsen, S.A. Halse and R.C. Thompson, Morphological and molecular characterization of Giardia isolated from the straw-necked ibis (Threskiornis soinicollis) in Western Australia, J. Parasitol. 82 (1996), pp. 711-718.

Monis and Thompson, 2003 P.T. Monis and R.C.A. Thompson, Cryptosporidium and Giardia-zoonosis: fact or fiction?, Inf. Gen. Evol. 3 (2003), pp. 233-244.

Monis et al., 1996 P.T. Monis, G. Mayrhofer, R.H. Andews, W.L. Homan, W.L. Limper and P.L. Ey, Molecular genetic analysis of Giardia duodenalis isolates at the glutamate dehydrogenase locus, Parasitology 112 (1996), pp. 1-12.

Monis et al., 1998 P.T. Monis, R.H. Andrews, G. Mayrhofer, J. Mackrill, J. Kulda, J.L. Isaac-Renton and P.L. Ey, Novel lineages of Giardia intestinalis identified by genetic analysis of organisms isolated from dogs in Australia, Parasitology 116 (1998), pp. 7-19.

Monis et al., 1999 P.T. Monis, R.H. Andrews, G. Mayrhofer and P.L. Ey, Molecular systematics of the parasitic protozoan Giardia duodenalis, Mol. Biol. Evol. 16 (1999), pp. 1135-1144.

Olson et al., 2004 M. Olson, R. O'Handley, B. Ralston and R.C.A. Thompson, Emerging issues of Cryptosporidium and Giardia infections in cattle, Trends Parasitol. 20 (2004), pp. 185-191.

Ramesh et al., 2005 M.A. Ramesh, S.B. Malik and J.M. Logsdon Jr, A phylogenomic inventory of meiotic genes; evidence for sex in Giardia and an early eukaryotic origin of meiosis, Curr. Biol. 15 (2005) (2), pp. 185-191. 
Read et al., 2004 C. Read, P.T. Monis and R.C.A. Thompson, Discrimination of all genotypes of Giardia duodenalis at the glutamate dehydrogenase locus using PCR-RLFP, Infect. Genet. Evol. 4 (2004), pp. 125-130.

Sogin et al., 1989 M.L. Sogin, J.H. Gunderson, H.J. Elwood, R.A. Alonson and D.A. Peattie, Phylogenetic meaning of the kingdom concept: an unusual ribosomal RNA from Giardia lamblia, Science 243 (1989), pp. 75-77.

Thompson, 2004 R.C.A. Thompson, The zoonotic significance and molecular epidemiology of Giardia and giardiasis, Vet. Parasitol. 126 (2004), pp. 15-35.

Thompson et al., 2000 R.C.A. Thompson, R.M. Hopkins and W.L. Homan, Nomenclature and genetic groupings of Giardia infecting mammals, Parasitol. Today 16 (2000), pp. 210-213.

Traub et al., 2004 R.J. Traub, P.T. Monis, I. Robertson, P. Irwin, N. Mencke and R.C.A. Thompson, Epidemiological and molecular evidence supports the zoonotic transmission of Giardia among humans and dogs living in the same community, Parasitology 128 (2004), pp. 253-262.

Trout et al., 2004 J.M. Trout, M. Santin, E. Greiner and R. Fayer, Prevalence of Giardia duodenalis genotypes in preweaned dairy calves, Vet. Parasitol. 124 (2004), pp. 179-186.

Upcroft et al., 1994 J.A. Upcroft, A. Healey and P. Upcroft, A new rDNA repeat unit in human Giardia, J. Eukaryot. Microbiol. 41 (1994), pp. 639-642.

van Keulen et al., 1993 H. van Keulen, R.R. Gutell, M.A. Gates, S.R. Campbell, S.L. Erlandsen, E.L. Jarroll, J. Kulda and E.A. Meyer, Unique phylogenetic position of Diplomonadida based on the complete small subunit ribosomal RNA sequence of Giardia ardeae, G. muris, G. duodenalis and Hexamita sp, Fed. Am. Soc. Exp. Biol. J. 7 (1993), pp. 223-231.

van Keulen et al., 1995 H. van Keulen, W.L. Homan, S.L. Erlandsen and E.L. Jarroll, A three nucleotide signature sequence in small subunit rRNA divides human Giardia in two different genotypes, J. Eukaryot. Microbiol. 42 (1995), pp. 392-394.

van Keulen et al., 1998 H. van Keulen, D.E. Feely, P.T. Macechko, E.L. Jarroll and S.L. Erlandsen, The sequence of Giardia small subunit rRNA shows that voles and muskrats are parasitized by a unique species Giardia microti, J. Parasitol. 84 (1998), pp. 294-300.

van Keulen et al., 2002 H. van Keulen, P.T. Macechko, S. Wade, S. Schaaf, P.M. Wallis and S.L. Erlandsen, Presence of human Giardia in domestic, farm and wild animals, and environmental samples suggests a zoonotic potential for giardiasis, Vet. Parasitol. 108 (2002), pp. 97-107.

Yong et al., 2000 T.S. Yong, S.J. Park, U.W. Hwang, H.W. Yan, K.W. Lee, D.Y. Min, H.J. Rim, Y. Wang and F. Zheng, Genotyping of Giardia lamblia isolates from humans in China and Korea using ribosomal DNA Sequences, J. Parasitol. 86 (2000), pp. 887-891. 